\section{Soviet sanctions}

SiR - I welcome your leading article of 7 January (p.1) and in particular your criticism of the suspension of the exchange agreement between the United States and the Soviet Union.

Such a suspension must surely weaken world peace. The merits and demerits of unilateral nuclear disarmament are much debated but the prior need is for a better understanding between peoples of different cultures - in this case the United States/United Kingdom and the Soviet Union. The risk of scientists "having their brains picked" surely matters less than the potential benefits from better knowledge of human beings of the "other" culture - their hopes, fears and hang-ups.

As a first line of defence for international understanding and peace, scientific and other exchanges can be good investments and should be fostered, not reduced. Their costs, if prohibitive to self-financing individuals, are infinitesimal compared with those of armaments.

\section{Abingdon, $U K$}

H.J. KILLICK

\section{Ethnic journal}

SIR - H.H. Hirschhorn (Nature 14 January, p.92) appears to have misunderstood the "small niche" to which Journal of Ethnopharmacology is trying to lay claim, even though my review quoted the aims of the journal in full. Rather than being another journal of pharmacognosy, which I would accept could appear to be of greater importance than all the drugs for the cardiovascular system, J. Ethnopharmacology specializes in the use of drugs by ethnic cultures. How does the importance of "ceramic use for prehistoric Datura use in $\mathrm{N}$. America" compare with a typical paper from Journal of Cardiovascular Pharmacology?

The number of reprint requests might reflect more accurately the obscurity of the journal and difficulty in finding it in a library, than the importance of the subject.

St Bartholomew's Hospital, Hilary G. Pickles

London, UK

\section{Anthrax island}

SIR - The paper by Manchee et al. ${ }^{1}$ provides the first published quantitative information about the the contamination of Gruinard Island with anthrax spores. In view of the public interest and concern that have been expressed, this is welcome. Nevertheless, the information given is meagre and the main tentative conclusion questionable.

Since no accurate viable counts of spores were made on samples taken before those reported on in the paper, it is impossible to estimate the time course of the contamination. The authors consider that its present extent warrants their taking seriously van Ness's assumption ${ }^{2}$ that significant multiplication of anthrax bacilli may occur in the soil. However, neither in that paper, nor in a series of earlier papers, does van Ness cite experimental evidence to justify this assumption. In support, he quotes a paper by Minett and
Dhanda ${ }^{3}$. But those authors actually come to the opposite conclusion - that the anthrax bacillus does not behave as a saprophyte in nature.

In the past, I have exhumed and examined cadavers of cattle that have died of anthrax, but I failed to isolate anthax from any, even from one buried as little as three months previously. The conditions - high ambient temperatures and the availability of blood and tissues from the cadavers for the nutrition of the anthrax bacilli - resembled those postulated by Manchee et al. ${ }^{1}$ as being likely to promote an increase of bacilli and spores in the soil. However, those familiar with the epizootiology of anthrax tend rather to regard such conditions as favourable to the increase of soil microflora inimical to anthrax organisms; a view which practical experience reinforces.

There is little experimental evidence to support either van Ness's view or the more conventional opinion that anthrax does not behave as a saprophyte. Unfortunately, incentives to investigate the ecology of the anthrax bacillus have diminished - despite its intrinsic interest - because of the ease with which anthrax can be controlled by the vaccine I developed ${ }^{4}$.

Attention should be paid to studying factors which could be responsible for the exceptionally long survival of the contamination of Gruinard Island. Is this related, for example, to the form in which the spores were distributed; to their number; to the character of the soil or of the soil microflora; to the lack of husbandry; or to climatic conditions? It would be deplorable if the special circumstances on Gruinard Island were not used to provide answers to these neglected ecological questions, and particularly to the question as to whether the anthrax bacillus can multiply sufficiently in the soil for this to be a significant factor in the epizootiology of anthrax. Practical experience in the control of anthrax does not support this view.

\section{Sarisbury Green,}

Hants, UK

1. Manchee, R.J., Broster, M.G., Melling, J., Henstridge, R.M. \& Stagg, A.J. Nature 294, 254-255 (1981). Van Ness, G.B. Science 72, 1303-1307 (1971).

3. Minett, F.C. \& Dhanda, M.R. Indian J. vet. Sci. 11, 308-328 (1941).

4. Sterne, M. Onderstepoorte J. vet. Sci. Anim. Ind. 21 41-43 (1946)

\section{No change in RE}

SIR - D.B. Jack and M.R. Gregg (Nature 22 October 1981, p.602) have used Flesch's index of reading ease (RE) to suggest that letters to Nature became harder to read at some time between 1940 and 1950 . Using the first hundred words in each letter as the criterion, the papers analysed from the years 1950 to 1980 were, on average, 15.44 index points more difficult (the harder to read the lower the index).

This conclusion obscures a difference of style between earlier and more recent letters to Nature, that of the way in which the opening paragraph is used by authors. Current practice demands that the opening paragraph shall serve two functions, both as introduction and as a summary of the main conclusions. In its latter function it must often be laden with a burden of latinate technical terms and exactitudes, for those readers who choose to go further. The earlier style demanded simply that the opening paragraph served to whet the appetite and to lead the reader gently to the nub of the matter, eschewing difficulties at first.

I have therefore computed Flesch's RE for the first and second paragraphs of two samples of 20 letters each, culled from Nature of October 1981 and of October 1931. If the second paragraph contained less than a hundred words the third paragraph was lumped with it.

\begin{tabular}{cccc}
\hline \multicolumn{4}{c}{ Reading ease } \\
& Para 1 & Para 2 & Total text \\
1931 & $29.8 \pm 4.3$ & $23.7 \pm 4.1$ & 26.3 \\
1981 & $15.1 \pm 2.1$ & $21.0 \pm 2.4$ & 18.5 \\
\hline
\end{tabular}

This analysis confirms Jack and Gregg's conclusion that the opening sentences today are more difficult than they were 50 years ago. In my sample the difference is $14.7 \mathrm{RE}$ points. The 50 year difference for the second paragraph, however, is a mere 2.7 points which is not statistically significant. In 1931 the second paragraph was on average 6.1 points more difficult than the introduction; today it is 5.9 points easier.

Authors today seem not to be cloaking their findings in obscure language significantly more than they did 50 years ago, except in the introduction.

\section{Environment Canada,} Ottawa, Canada

\section{More repeats}

SIR - There appear to be two homologous sequences in a single exon of the collagen $\alpha 2$ (1) sequences reported by Wozney et al. in Nature of 12 November $1981^{1}$.

The sequences occur in a single polypeptide and are apparent in the nucleotide sequence but not the amino acid sequence. A span of 36 nucleotides is repeated with six differences (marked with $\times$ ):

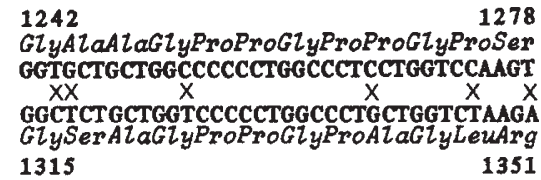

1315

The differences are probably due to post duplication mutations.

The sequences lie 4 collagen units, $\left(\mathrm{Gly}-\mathrm{X}_{\mathrm{i}}-\mathrm{Y}\right)_{4}$, from each other and contain 4 collagen units each, which makes a 54 base pair $(\mathrm{bp})$ repeat hard to credit. I cannot think of a plausible scheme to yield 36 bp repeats from 54 bp units. Apparently 36 bp were extracted by double unequal crossover and reappended $36 \mathrm{bp}$ further down the molecule leading to the internal homology.

Michael P. FinerTy

Tucson, Arizona, USA

1. Wozney, J., Manahan, D., Tate, V., Boedtker, H. \& Doty, P. Nature 294, 129-135 (1981) 